\title{
Systematiske oversikter om effekt av tiltak
}

\author{
Gro Jamtvedt
}

\author{
Avdeling for kunnskapsoppsummering, Nasjonalt kunnskapssenter for helsetjenesten \\ E-post: grj@nokc.no Telefon: 97518155
}

\begin{abstract}
SAMMENDRAG
Systematiske oversikter er en forutsetning for kunnskapsbaserte beslutninger fordi de gir en samlet oversikt over forskningsstatus for den aktuelle problemstillingen. En systematisk gjennomgang av eksisterende forskning kan generere ny innsikt, identifisere kunnskapshull og vise vei for videre forskning. Fremgangsmåten for å utarbeide en systematisk oversikt kjennetegnes av 1) et klart formål med forhåndsdefinerte kriterier for inklusjon av studier, 2) en eksplisitt, reproduserbar framgangsmåte (metode), 3) en omfattende søkestrategi der målet er å identifisere alle studier som tilfredsstiller inklusjonskriteriene, 4) en vurdering av validiteten til resultatene i inkluderte studier, og 5) en systematisk framstilling og sammenstilling av kjennetegn og resultater fra de inkluderte studiene. Randomiserte kontrollerte studier har en sentral plass i systematiske oversikter om effekt av tiltak, men også andre typer effektforskning kan være aktuelle å inkludere. Nasjonalt kunnskapssenter for helsetjenesten produserer systematiske oversikter til støtte for helsepolitiske beslutninger, nasjonale retningslinjer og kunnskapsbasert praksis. Fremgangsmåten er beskrevet i håndboka "Slik oppsummerer vi forskning" som er tilgjengelig på Kunnskapssenterets nettside. Kunnskapssenteret bidrar også i det internasjonale arbeidet med å utarbeide systematiske oversikter gjennom publisering i Cochrane- og Campbell-databasene og i vitenskapelige tidsskrift.
\end{abstract}

\section{Jamtvedt G. Systematic reviews on the effect of interventions. Nor J Epidemiol 2013; 23 (2): 119-124.}

\section{ENGLISH SUMMARY}

Systematic reviews are a prerequisite for evidence informed decisions because they provide a comprehensive review of what is known on the particular topic in question. By systematically reviewing existing research findings, new insights can be generated, knowledge gaps identified, and directions for future research found. The methods for developing a systematic review are characterised by 1) a clearly stated objective and pre-defined eligibility criteria for studies, 2) the use of explicit, reproducible methods, 3) a systematic search to identify all studies that would meet the eligibility criteria, 4) an assessment of the validity of the findings of the included studies, 5) a systematic presentation and synthesis of the characteristics and findings of the included studies. Randomized controlled trials play a key role in systematic reviews of the effectiveness of interventions, but other types of effectiveness-studies may also be relevant to include. The Norwegian Knowledge Centre for the Health Services produces systematic reviews to support well informed health policy making, clinical practice guidelines-development, and to contribute to evidence-based practices. The methods are described in the handbook "Slik oppsummerer vi forskning" ["This is how we summarise research"], which is available online. The Knowledge Centre is also engaged in the wider global effort to produce systematic reviews, by preparing Cochrane- and Campbell-reviews, as well as systematic reviews that are published through regular scientific journals.

This is an open access article distributed under the Creative Commons Attribution Licence, which permits unrestricted use, distribution, and reproduction in any medium, provided the original work is properly cited.

\section{INNLEDNING}

For de fleste problemer finnes et utall av løsningsforslag. Mange har meninger om hva som bør gjøres, enten det er snakk om å lindre kløende myggstikk, forebygge forkjølelse, redusere behandlingskøer i sykehusene, hindre at ungdom dropper ut av videregående skole, eller bekjempe vold og kriminalitet.

Hva kan vi egentlig tro på om virkningene av de mange tiltakene som foreslås? Hvordan kan vi være noenlunde sikre på at vi får en nøktern framstilling av fakta, og ikke et ensidig partsinnlegg?

Uten å få vite kunnskapsgrunnlaget for de tiltak som presenteres kan vi ikke være trygge på at påstandene som framsettes er godt funderte.
I medisin og helsefag er det lang tradisjon for at fagtidsskrifter publiserer oversiktsartikler om en problemstilling, men kravene til vitenskapelig kvalitet for slike arbeider har vært mangelfulle. Det var først på 1980-tallet at Andy Oxman og andre pekte på alvorlige metodologiske problemer i oversiktsartikler på helsefeltet, og de negative konsekvensene dette kan ha, for eksempel ved at konklusjonene og anbefalingene kunne være misvisende (1-3). I løpet av de siste 20-30 årene har det vært en omfattende metodeutvikling som har satt nye standarder til hva som bør forventes av systematikk og vitenskapelighet i oversiktsartikler (4).

I dag regnes systematiske oversikter som en forutsetning for kunnskapsbaserte beslutninger, både innen klinisk virksomhet og i utforming av helsepolitikk. 
Tabell 1. Helsefaglige kjernespørsmål og måter man går fram på i forskning for å svare på dem (9).

\begin{tabular}{l|l}
\hline Kjernespørsmål & Foretrukket design \\
\hline $\begin{array}{l}\text { Hvor mange har en sykdom eller et problem? (spørsmål om forekomst) } \\
\text { Hvorfor blir noen syke, mens andre holder seg friske? (spørsmål om årsak) }\end{array}$ & $\begin{array}{l}\text { Tverrsnittsstudier, surveys } \\
\text { Kohortstudier eller kasus-kontroll-design } \\
\text { Tvordan avgjøre om en person er syk eller har et bestemt problem? (spørsmål } \\
\text { om diagnostikk) }\end{array}$ \\
$\begin{array}{l}\text { Hva er positive og negative effekter av forebygging, behandling, organisering } \\
\text { av tjenester eller andre tiltak? (spørsmål om effekt) } \\
\begin{array}{l}\text { Randomiserselser (med en } \\
\text { Hvordan vil det sannsynligvis gå med en pasient med en bestemt lidelse? }\end{array}\end{array}$ & Kohortstudier \\
$\begin{array}{l}\text { (spørsmål om prognose) } \\
\text { Hvordan oppleves det å leve med dette problemet? (spørsmål om opplevelse, }\end{array}$ & Kvalitative forskningsmetoder \\
\hline
\end{tabular}

\section{HVA KJENNETEGNER EN SYSTEMATISK OVERSIKT?}

Det enkleste kjennetegnet på en systematisk oversiktsartikkel er at den er bygget opp på tilsvarende vis som de aller fleste andre vitenskapelige publikasjoner: Først en introduksjonsdel, deretter en metodebeskrivelse, resultater og til slutt en diskusjon. Beskrivelsen av metodene som har vært benyttet skal være så detaljert at leseren i prinsippet skal ha mulighet til å etterprøve og vurdere det som er gjort. En systematisk oversikt defineres gjerne som et forsøk på å: "collate all empirical evidence that fits pre-specified eligibility criteria in order to answer a specific research question. It uses explicit, systematic methods that are selected with a view to minimizing bias, thus providing more reliable findings from which conclusions can be drawn and decisions made" (5).

Viktige begrep i denne definisjonen er "empirisk forskning", "eksplisitt" og "systematisk". I en systematisk oversikt brukes eksplisitte og systematiske metoder både for å identifisere, velge ut, vurdere, sammenstille og gradere data fra empirisk forskning. En systematisk oversikt skal ha (5):

- Et klart formål med forhåndsdefinerte kriterier for inklusjon av studier

- En eksplisitt, reproduserbar framgangsmåte (metode)

- En omfattende søkestrategi der målet er å identifisere alle studier som tilfredsstiller inklusjonskriteriene

- En vurdering av validiteten til resultatene i inkluderte studier

- En systematisk framstilling og sammenstilling av kjennetegn og resultater fra de inkluderte studiene.

\section{HVORFOR TRENGER VI SYSTEMATISKE OVERSIKTER?}

Tatt $\mathrm{i}$ betraktning at det for eksempel i snitt publiseres over 75 randomiserte kontrollerte forsøk hver eneste dag (6) er det praktisk umulig for helsepersonell å holde seg faglig oppdatert gjennom lesing av enkeltstudier. Systematiske oversikter gir et samlet bilde av kunnskapen: de klargjør hva vi vet og ikke vet, idenifiserer kunnskapshull og viser vei for videre forskning (7).

Erkjennelsen av at systematiske oversikter er viktige som kunnskapsgrunnlag for politikk og praksis førte blant annet til opprettelsen av Nasjonalt kunnskapssenter for helsetjenesten (Kunnskapssenteret) i 2002.
Kunnskapssenterets samfunnsoppdrag er å bidra til gode beslutninger i helsespørsmål ved at det "oppsummerer relevant forskningsbasert kunnskap på en systematisk måte og gjør resultatene tilgjengelig" (8). Systematiske oversikter og metodevurderinger fra senteret brukes blant annet av grupper som utarbeider nasjonale retningslinjer for klinisk praksis, i Nasjonalt råd for kvalitet og prioritering $\mathrm{i}$ helse- og omsorgssektoren, og av helsemyndighetene når det utarbeides strategier for helsefremmende tiltak og for organisering av helsetjenester. Eksempler på tema i systematiske oversikter fra Kunnskapssenteret er: tidlig ultralyd i svangerskapet, bruk av heroin i behandling av personer med heroinavhengighet, innføring av rotavirusvaksinasjon i barnevaksinasjonsprogrammet, screening for svangerskaps- og barseldepresjon, organisering av psykisk helsevern, botilbud for personer med demens, rusforbyggende tiltak for barn og unge og effekten av et felles nødnummer.

\section{EFFEKT AV TILTAK}

Enten en jobber som helsebyråkrat, kliniker eller forsker er en vanligvis opptatt av ett tema om gangen, det være seg barn og astma, mental helse hos eldre eller organisering av skolehelsetjenesten. Av praktiske grunner er det nødvendig å spesifisere hvilke spørsmål vi er interesserte i, eller hva slags informasjon som er aktuell, når vi skal bruke forskning. Er det forekomsten av barneastma vi er opptatt av, eller årsakene til astma, prognosen, eller hva som kan gjøres for å forebygge astmaanfall? Kanskje er vi heller ute etter kunnskap om hvordan det oppleves å leve med astma? Disse forskjellige typene spørsmål kalles ofte for kjernespørsmålene i helsetjenesten - se tabell 1 (9).

I prinsippet kan det utarbeides systematiske oversikter for alle typer spørsmål. Systematiske oversikter som dreier seg om effekt av tiltak er imidlertid det vanligste. For politikkutforming og for kliniske beslutninger er kunnskap om virkningene av tiltak svært viktig, ikke minst for å sikre seg mot at det som gjøres er mer skade enn gagn.

\section{Å UTARBEIDE EN SYSTEMATISK OVERSIKT}

Fremgangsmåtene for å produsere en god systematisk oversikt er beskrevet mange steder $(5,10,11)$. Kunnskapssentrets egen håndbok, "Slik oppsummerer vi 
forskning" (12), er i stor grad basert på Cochrane Handbook for Systematic Reviews of Interventions (5). Sentrale prinsipper her er systematikk og åpenhet. Systematikken skal redusere risiko for feilkilder, både $\mathrm{i}$ forbindelse med søk etter studier, utvelgelse og vurdering av studier, og i sammenstillingen av resultatene. Åpenhet skal gi innsyn i hvilke metoder som er brukt, og hvorfor og hvordan resultatene ble som de ble.

Et fornuftig første skritt før en setter i gang arbeidet er å undersøke om noen allerede har gjort jobben unødig dobbeltarbeid bør unngås. Et litteratursøk i DARE (the Database of Abstracts of Reviews of Effects) og i CDSR (the Cochrane Database of Systematic Reviews) vil raskt avdekke om så er tilfelle. I PROSPERO-databasen ligger det informasjon om systematiske oversikter som er under utarbeidelse (www.crd.york.ac.uk/Prospero/).

Arbeidet med å utarbeide en systematisk oversikt starter med å utvikle en protokoll der problemstillingen og fremgangsmåten som skal benyttes for å finne, samle og analysere data, blir beskrevet. Protokollen for en systematisk oversikt er like sentral som den er for en klinisk studie. Utformingen av protokollen kan være omfattende og tidskrevende og det er viktig å involvere fageksperter i denne fasen. Klinikere og pasienter kan bidra til å sikre at problemstillingen formuleres slik at den blir så relevant som mulig og at viktige utfallsmål tas med. Protokoller for Cochrane- og Campbell-oversikter gjennomgår omfattende fagfellevurderinger og blir deretter publisert. Ekstern fagfellevurdering benyttes også for Kunnskapssenterets protokoller for systematiske oversikter.

Utarbeidingen av systematisk oversikt kan skisseres som en trinnvis prosess (12).

\section{FORMULERE SPØRSMÅL OG SELEKSJONS- KRITERIER}

Et nyttig hjelpemiddel når vi formulerer problemstillingen i en systematisk oversikt om effekt av tiltak, er forkortelsen "PICO", som står for "Population Intervention - Comparison - Outcome" (12). De valg som gjøres for hver av disse komponentene definerer hva den systematiske oversikten vil omhandle, og legger premissene for det videre arbeidet: Hvilken pasientgruppe (population) er det snakk om? Hvilke tiltak (interventions)? Sammenliknet med hva (comparison)? Og hva er det en ønsker å oppnå (outcome)? Problemstillingen kan da, for eksempel, formuleres slik: "Formålet med denne oversikten er å sammenstille effekten av et kostholdsprogram for barn med overvekt sammenlignet med ikke noe program, med tanke på vektreduksjon". Ut fra PICO-komponentene følger også mange av kriteriene som vil bli brukt for inklusjon av studier i den systematiske oversikten (12). I tillegg må det besluttes hva slags typer studier som skal inkluderes. Noen forskningsdesign er mer egnet enn andre til å besvare spørsmål om effekt av tiltak. Randomiserte kontrollerte studier er som regel det

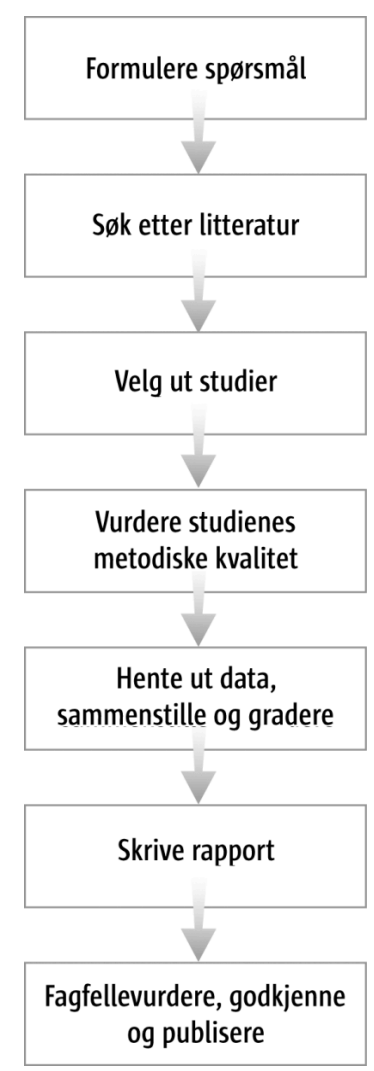

Figur 1. Trinnene i en systematisk oversikt (12).

foretrukne designet fordi det antas å gi mest pålitelig informasjon (13). Dersom den systematiske oversikten omhandler spørsmål om annet enn effekt vil andre forskningsdesign være å foretrekke. For eksempel belyses spørsmål om årsaker til sykdom best av kasuskontroll- eller kohort-studier (12). Randomiserte kontrollerte studier er dessuten dårlig egnet til å avdekke kunnskap om sjeldne konsekvenser av et tiltak, for eksempel bivirkninger (5) - kohortstudier kan her være mer hensiktsmessige. For en del problemstillinger er det utført få eller ingen randomiserte kontrollert studier. Dette er, for eksempel, ofte tilfelle når det gjelder organisatoriske, helsefremmende og forebyggende tiltak. Når Kunnskapssenteret lager oversikter som omhandler tiltak på disse områdene vil det ofte være aktuelt også å inkludere kvasieksperimentelle studier, som kontrollerte før og etter studier (uten randomisering) og avbrutte tidsserieanalyser (5).

\section{SØKE ETTER LITTERATUR}

Et systematisk litteratursøk er en forutsetning for å kunne produsere en god systematisk oversikt. Bibliotekarer med kompetanse i å utføre systematiske søk har en sentral rolle å spille her, spesielt når det gjelder valg av kilder (i første rekke elektroniske databaser) og utforming av søkestrategi. Det er hundrevis av databaser å velge blant (5). Noen av dem, som MEDLINE/ PubMed og EMBASE, dekker alle områder av helsetjenesten. Andre databaser er rettet mot begrensete 


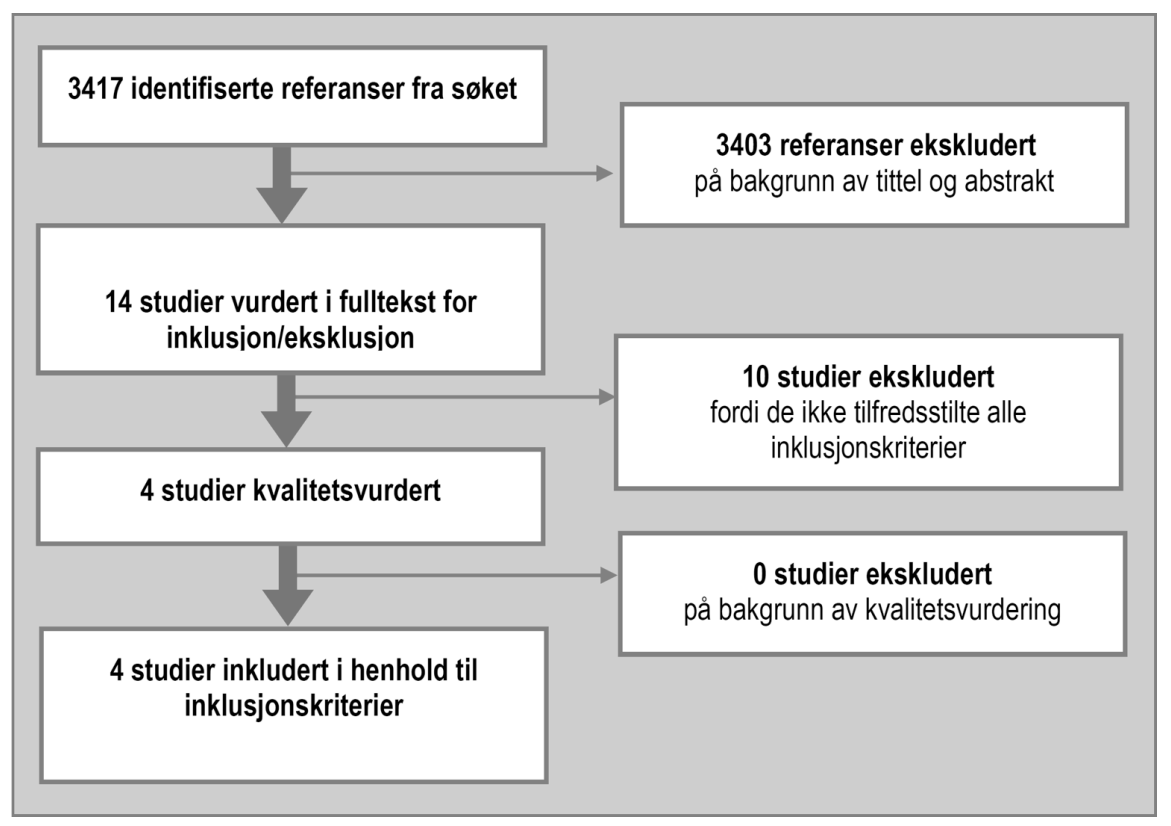

Figur 2. Eksempel på flytskjema (12).

tema eller et fagområde. De tre databasene MEDLINE, EMBASE, og CENTRAL regnes gjerne som de viktigste kildene for systematiske oversikter som omhandler effektspørsmål (5), men det vil ofte være aktuelt å søke i andre databaser også. For mer detaljert informasjon om søk i databaser, se artikkelen til Kirkehei og Ormstad i denne utgaven av Norsk epidemiologi (14). I tillegg til å gjøre systematiske littertursøk vil det også være aktuelt å forsøke å identifisere studier på andre måter, for eksempel ved gjennomgang av referanselister i aktuelle artikler, kontakt med fageksperter osv.

\section{VELGE UT STUDIER OG VURDERE KVALITET}

Utvelgelsen av studier gjøres av to personer som arbeider uavhengig av hverandre. Disse vurderer studienes relevans i forhold til PICO-kriteriene som er beskrevet i protokollen, og hvorvidt studiedesignet er i tråd med inklusjonskriteriene. Gjennom trinnvis vurdering av titler, sammendrag og fulltekstartikler skilles studier som ikke er relevante fra dem som er relevante for problemstillingen. Avhengig av om søket i utgangspunktet var bredt (sensitivt) eller smalt (spesifikt), kan det være snakk om mange tusen titler og sammendrag som gjennomgås og forkastes. Til slutt er det gjerne en håndfull studier igjen som oppfyller inklusjonskriteriene. Gangen i denne prosessen bør dokumenteres og presenteres ofte i et flytdiagram (12). En liste over ekskluderte studier med begrunnelse for eksklusjon hører også med.

Dataekstraksjon er prosessen der forfatterne henter ut nødvendig informasjon fra hver av de inkluderte studiene, for eksempel om deltakerne (land, alder, kjønnsfordeling), om tiltaket som ble prøvet ut (dosering av legemidler, eventuell tilleggsbehandling osv), og resultatene (5). $\AA$ trekke ut resultatene for hver sammenligning og hvert utfall er en omfattende og viktig prosess som krever grundighet og kvalitetssikring. Et minimumskrav bør være at én forsker trekker ut data fra artiklene og at en annen forsker sjekker at tallene stemmer.

Den metodiske kvaliteten av studiene som inngår i en systematisk oversikt kan ha stor betydning for hvor stor tillit vi har til resultatene. Vurderingen av studienes metodiske kvalitet er derfor et viktig trinn $i$ prosessen. Det er her snakk om å vurdere intern validitet av resultatene i hver av de enkelte studiene. Dette kan gjøres på mange måter, og flere metoder har vært benyttet for dette formålet. I Cochrane Collaboration ble det for få år siden besluttet å benytte en "risk of bias"-tilnærming for å vurdere hvor stor tiltro en bør ha til resultatene fra en studie $(5,12)$. For hvert av følgende seks domener gjøres en vurdering av hvorvidt det er høy, lav eller uklar risiko for systematiske feil (bias) i gjennomføring av studien: generering av randomiseringssekvens, skjult fordeling til grupper, blinding, ufullstendige data, manglende rapportering om utfallsmål, eller andre kilder til systematiske skeivheter (5). Basert på disse vurderingene anslås en samlet "risk of bias" for hvert enkelt studieresultat, og for det samlete dokumentasjonsgrunnlaget (5).

\section{SAMMENSTILLE OG GRADERE RESULTATER}

Resultater på tvers av de inkluderte enkeltstudiene sammenstilles for hver sammenlikning (dersom det er mer enn to tiltak som vurderes opp mot hverandre), og for hvert utfallsmål. Sammenstillingen kan gjøres deskriptivt (ikke-kvantitativt), eller - når det ligger til rette for det - ved hjelp av statistiske teknikker for å slå sammen resultatene av inkluderte studier kvantitativt (metaanalyse). Dette vil ofte øke den statistiske 
styrken i datamaterialet. Det er mange eksempler på at metaanalyse av flere, mindre studier kan avdekke en sikker og tydelig effekt. Ett eksempel er metaanalysen om effekten av ergoterapi for å bedre utfall hos pasienter med hjerneslag (15). En serie av randomiserte kontrollerte fors $ø \mathrm{k}$ av denne problemstillingen var blitt utført, men hver for seg var det ikke mulig å trekke noen sikre konklusjoner fra disse studiene. En metaanalyse av alle studieresultatene dokumenterte en rekke viktige effekter av ergoterapi. Nærmere omtale av metaanalyser er gitt i Smedslunds artikkel i dette nummeret av Norsk Epidemiologi (16).

I en deskriptiv analyse vurderes effektene av tiltakene basert på en vurdering av hvor godt samsvar det er mellom resultatene fra de inkluderte studiene, samt retningen og størrelsen på effektestimatene.

Systematiske oversikter over kvalitative studier er noe relativt nytt, men det er publisert flere slike arbeider de siste årene. Det å oppsummere erfaringer og opplevelser blant dem som berøres av et tiltak (pasienter, helsepersonell) kan være svært viktig i seg selv, og ikke minst et nyttig supplement til systematiske oversikter om effekt av tiltak. I noen tilfeller kombineres kvantitative og kvalitative metoder - såkalte "mixed-mehods"-oversikter (17). Berg og medarbeidere har en utdypende artikkel om systematisk oppsummering av kvalitativ forskning i dette nummeret av Norsk Epidemiologi (18).

GRADE (the Grading of Recommendations Assessment, Development and Evaluation) er en metode for å gradere kvaliteten på dokumentasjonen i systematiske oversikter, og til å gradere styrken på anbefalinger som gis i retningslinjer (19). Kunnskapssenteret og internasjonale organisasjoner som Cochrane Collaboration og Verdens helseorganisasjon (WHO) bruker GRADE i sitt arbeid. Ett viktig kjennetegn ved GRADE-metoden er at vurderingene som ligger til grunn for graderingen av kvaliteten på dokumentasjon blir presentert eksplisitt for leseren (19). Dette er viktig ettersom det alltid vil være et element av skjønn i slike vurderinger. De viktigste elementene som inngår i kvaliteten på dokumentasjonen som vurderes er studiedesign (randomiserte forsøk, observasjonelle studier), risiko for systematiske feil (bias), grad av samsvar mellom studier (konsistens), hvor presise resultatene er (bredde på konfidensintervall) og om det er grunn til å mistenke rapporteringsskjevheter (19). I GRADE benyttes følgende kategorier for gradering av kvaliteten på dokumentasjonen:

Hoy kvalitet: Vi har stor tillit til at effektestimatet ligger nær den sanne effekten.

Middels kvalitet: Vi har middels tillit til effektestimatet: Effektestimatet ligger sannsynligvis nær den sanne effekten, men effektestimatet kan også være vesentlig ulikt den sanne effekten.

Lav kvalitet: Vi har begrenset tillit til effektestimatet: den sanne effekten kan være vesentlig ulikt den sanne effekten.

Svart lav kvalitet: Vi har svært liten tillit til at effektestimatet ligger nær den sanne effekten.

\section{FAgfelleVurdere og PUBLISERE}

Systematiske oversikter som utarbeides av Kunnskapssenteret gjennomgår ekstern fagfellevurdering før publisering på Kunnskapssenterets nettsider. Arbeider som publiseres som vitenskapelige artikler i tidsskrift eller i Cochrane- og Campbell-databasene gjennomgår samme kvalitetskontroll som andre vitenskapelige publikasjoner, inklusive fagfellevurdering.

The PRISMA Statement (20) inneholder en 27 punkts sjekkliste for hva en systematisk oversiktsartikkel bør inneholde, og hvordan den bør utformes.

\section{REFERANSER}

1. Oxman AD, Guyatt GH. Guidelines for reading literature reviews. Can Med Assoc J 1988; 138: 697-703.

2. Mulrow CD. Rationale for systematic reviews. BMJ 1994; 309: 597-599.

3. Oxman AD, Guyatt GH. The science of reviewing research. Ann N Y Acad Sci 1993; 703: 125-133.

4. The Editorial Team. Cochrane Methodology Review Group. About The Cochrane Collaboration (Cochrane Review Groups (CRGs) 2012, Issue 3. Art. No.: METHOD.

5. Higgins JPT, Green S (eds). Cochrane Handbook for Systematic Reviews of Interventions Kapittel 1, 2, 5, 6 og 8, Version 5.1.0 [oppdatert mars 2011]. The Cochrane Collaboration, 2011. www.cochrane-handbook.org (07.06.2013).

6. Bastian H, Glasziou P, Chalmers I. Seventy-five trials and eleven systematic reviews a day: how will we ever keep up? PLoS Med 2010;7:e1000326.

7. Norderhaug IN, Mørland B, Jamtvedt G. Informasjon om kunnskapshull fra Kunnskapssenterets systematiske oversikter og HTA-rapporter publisert i 2011. Notat fra Kunnskapssenteret 2012. Oslo: Nasjonalt kunnskapssenter for helsetjenesten, 2012.

8. Kunnskapssenterets vedtekter: www.kunnskapssenteret.no/Mer+om+oss/Vedtekter (07.06.2013).

9. Jamtvedt G, Hagen KB, Bjørndal A. Kunnskapsbasert fysioterapi. Metoder og arbeidsmåter. Gyldendal akademisk, 2003.

10. Systematic reviews. CRDs guidance on undertaking reviews in health care. Centre for Reviews and Dissemination, University of York, 2008. 
11. Utvärdering av metoder i hälso- och sjukvården. En handbok. 1. opplag. Stockholm: SBU - Statens beredning för medisinsk utvärdering, 2013.

12. Slik oppsummerer vi forskning. Håndbok for Nasjonalt kunnskapssenter for helsetjenesten. 4. reviderte utg. Oslo: Nasjonalt kunnskapssenter for helsetjenesten, 2013. www.kunnskapssenteret.no/Verkt $\% \mathrm{C} 3 \% \mathrm{~B} 8 \mathrm{y} /$ Slik+oppsummerer+vi+forskning.2139.cms (07.06.2013).

13. Odgaard-Jensen J, Vist GE, Timmer A, Kunz R, Akl EA, Schünemann H, et al. Randomisation to protect against selection bias in healthcare trials. Cochrane Database of Systematic Reviews 2011, Issue 4. Art. No.: MR000012. doi: 10.1002/14651858.MR000012.pub3.trials (Cochrane Methodology Review). I: The Cochrane Library, Issue 1, 2003. Oxford: Update Software.

14. Kirkehei I, Ormstad S. Litteratursøk. Norsk Epidemiologi 2013; 23: 141-145.

15. Legg L, Drummond A, Leonardi-Bee J, Gladman JR, Corr S, Donkervoort M, et al. Occupational therapy for patients with problems in personal activities of daily living after stroke: systematic review of randomised trials. BMJ 2007; 335: 922.

16. Smedslund G. Metaanalyse. Norsk Epidemiologi 2013; 23: 147-149.

17. Thomas J, Harden A. Methods for the thematic synthesis of qualitative research in systematic reviews. $B M C$ Medical Research Methodology 2008; 8: 45.

18. Berg R, Munthe-Kaas H. Systematiske oversikter og kvalitativ forskning. Norsk Epidemiologi 2013; 23: 131139.

19. Guyatt GH, Oxman AD, Vist GE, Kunz R, Falck-Ytter Y, Alonso-Coello P, Schünemann HJ, GRADE Working Group. GRADE: an emerging consensus on rating quality of evidence and strength of recommendations. BMJ 2008; 336: 924.

20. Moher D, Liberati A, Tetzlaff J, Altman DG; PRISMA Group. Preferred reporting items for systematic reviews and meta-analyses: the PRISMA statement. PLoS Med 2009; 6: e1000097. 